\title{
In The Beginning...
}

\section{Jacob E. Goodman ${ }^{1}$}

Received: 10 February 2020 / Published online: 25 February 2020

๑) Springer Science+Business Media, LLC, part of Springer Nature 2020

I met Ricky Pollack in 1960, when I started a position as instructor at the Bronx campus of NYU, which was at that time its main undergraduate college. I had graduated from the same college (my favorite teacher there being Harold N. Shapiro-later Ricky's thesis advisor!), so I knew my way around pretty well; and one of the first things I did when I learned that Ricky was a fellow music lover was to invite him to join me in the NYU library to listen to a recording by the Juilliard Quartet of the first two of Bartók's string quartets. We occasionally talked mathematics, but his interests were in number theory and mine in algebraic geometry, and it was not yet clear (to us!) how the two were intricately involved.

Over the next few years we socialized a bit, and I found that I enjoyed Ricky's company; he was clever, and loved to argue - both qualities that I enjoyed. But after I finished my Columbia degree and was appointed to an assistant professorship at City College, we seemed to drift apart.

In 1975, after a sabbatical during which I tried very hard, but unsuccessfully, to prove a conjecture of mine (which later turned out to be false!), I decided to take a vacation from algebraic geometry and work for a bit on the (not yet proven) four-color conjecture and a few other things, finally asking myself the following question: What is the simplest geometric object about which one can say something interesting? A single point did not quite do it, but a finite set of points-in general position in the plane, say - did: there was an essential difference between four points that formed the vertices of a quadrilateral and three points with a fourth inside their triangle. Obviously one could ask: how many "essentially different" configurations are there of $n$ points in the plane, and how can one describe them in a uniform way? This simple question, along with a way of encoding them by what I began to call an "allowable sequence of permutations" led me to call Ricky and ask whether he might be inclined to help me develop these ideas further. He was, and we began working together in 1978, at first alternating between the Courant Institute and City College, but soon just at the more convenient Institute. It turned out that Ricky had also been thinking about an easy-to-

Jacob E. Goodman

jgoodman@ccny.cuny.edu

1 San Rafael, CA, USA 
state but difficult-to-solve geometric problem: the Erdős-Szekeres Conjecture, so our collaboration began with these ideas in the forefront.

From that point on, we went on to work for the next few decades — at first just the two of us, much later on with additional co-authors: Boris Aronov, Imre Bárány, Saugata Basu, Sylvain Cappell, Raghavan Dhandapani, Andreas Holmsen, János Pach, Kristian Ranestad, Micha Sharir, Shakhar Smorodinsky, Frank Sottile, Bernd Sturmfels, Rafe Wenger, and Tudor Zamfirescu. But a second serendipitous event was soon to loom large in our collaboration.

In 1984 Ricky received a letter from a publisher (it may have been Cambridge University Press, but I'm no longer sure), asking whether he might be interested in exploring the idea of a journal devoted to discrete geometry. We talked about it, and-because one of our recent papers had included some results in the then nascent field of computational geometry, came up with the idea of starting a journal with the name "Discrete \& Computational Geometry." (I actually flirted with the idea of calling it simply "Geometry," but Ricky soon disabused me of that notion!) We decided not to limit ourselves to Cambridge Univ. Press, but to explore the idea of such a journal with several other publishers as well. The one that expressed the greatest interest in the project was Springer-Verlag, in the person of the never-to-be-forgotten Walter Kaufmann-Bühler. We worked out a plan with Walter to begin publication in 1986, assembled an impressive editorial board, and we were off!

At the same time, I became aware of the possibility of organizing a week-long joint AMS-IMS-SIAM Summer Research Conference, and decided that that would be a great opportunity to encourage the two groups our journal would address-discrete geometers and computational geometers - to meet one another, listen to each other's problems and results, and possibly begin working together. Ricky was easily persuaded that that made sense, both scientifically and "politically." Our proposal was accepted, and we set to work organizing the conference, which was generally considered a success. It turned out in the decades that followed that similar conferences, with the suffixes "Ten Years Later," "Twenty Years Later," and so on, have been equally successful (even if no longer sponsored by the same three organizations in recent years).

Ricky was very stimulating to work with. We soon devolved into a somewhat "adversarial" relationship: for example, I might come up with a wild idea, Ricky would challenge it, and either it would turn out to be nonsense (Ricky would "win"), or else I would wind up "ahead"; occasionally he would be the one to suggest something that would turn out to be fruitful, sometimes very much so. Each time we met, new ideas might pop up out of nowhere, and after a week went by they would either be shot down or else prevail. We soon began to think of this as a sort of "marriage," in which one or the other of us would win arguments. (I don't suggest this as a blueprint for working with a coauthor, but for us it did!).

Each of us worked occasionally in other areas, and sometimes with other co-authors. But together we wrote some 40 papers, and organized many conferences. We continued the co-editorship of DCG for 25 years, something that it is fair to say neither of us could ever have managed alone; we were both editors-in-chief and managing editors. The journal is now in younger hands and with a largely new Editorial Board (although 
some of its members have been with DCG from the beginning), and-I am happy to say—seems to be doing well.

Publisher's Note Springer Nature remains neutral with regard to jurisdictional claims in published maps and institutional affiliations. 